\title{
Comparison of Three Gravimetric-Geometric Geoid Models for Best Local Geoid Model of Benin City, Nigeria
}

\author{
Oduyebo, O. F. *; Ono M. N. and Eteje, S. O.
}

\author{
Department of Surveying and Geoinformatics, Nnamdi Azikiwe University, Awka, Nigeria \\ *Corresponding Author: jimioduyebo@yahoo.com
}

\begin{abstract}
The conversion of geometric as well as ellipsoidal heights from GNSS observations to practical heights for engineering constructions has necessitated the determination of the local geoid model of areas. Benin City is a developing area which requires a local geoid model for conversion of geometric heights to orthometric heights for physical developments in the area. This paper is on the best local geoid model of Benin City, Nigeria by comparing three gravimetric-geometric geoid models of the study area. GNSS and gravimetric observations were carried out on 49 points to respectively obtain their coordinates and absolute gravity values. The theoretical gravity values of the points were computed on the Clarke 1880 ellipsoid, subtracted from the absolute gravity values and corrected for the air (free air) to obtain the free air gravity anomalies of the points. The computed free air gravity anomalies were applied to compute the geoid heights of the points using the integration of the modified Stokes integral. Three geometric geoid surfaces (plane, second degree and third degree surfaces) were fitted to the computed gravimetric geoid heights using the least squares technique to obtain the gravimetric-geometric geoid models of the study area. The RMSE of the three gravimetric-geometric geoid models were computed to determine their (the models) accuracy. The three gravimetric-geometric geoid models were compared using their accuracy to obtain the most suitable geoid model of the study area. The results of the comparison showed that the third degree gravimetric-geometric geoid model is most suitable for application in the study area. It is recommended that ellipsoidal heights obtained from GNSS observation within Benin City, Nigeria should be converted to orthometric heights using the third degree geoid model.
\end{abstract}

Keywords-gravimetric, geometric, local, geoid, model.

\section{INTRODUCTION}

The Geoid is one of the Earth's shapes. Geoid surface is used to approximate the physical shape of the Earth. It is the equipotential surface of the Earth's gravity field which more or less coincides with mean sea level (Borge, 2013). Ubajekwe (2011) also defined the geoid as the equipotential surface of the earth's attraction and rotation which coincides on average with the mean sea level in the open Ocean. It is the surface which coincides with the mean sea level assuming that the sea was free to flow under the land in small frictionless channels. Ubajekwe (2011) explained further that the mean sea level is not quite an equipotential surface owing to non-gravitational forces (such as ocean currents, winds and barometric pressure variation). In geodetic surveying, the computation of the geodetic coordinates of points is commonly performed on a reference ellipsoid closely approximating the size and shape of the earth in the area of the survey. The actual measurements made on the surface of the earth with certain instruments are however referred to the geoid.
Moritz and Hofmann (2005) stated that the geoid coincides with that surface to which the oceans would conform over the entire earth if free to adjust to the combined effect of the earth mass attraction (gravitation) and the centrifugal force of the earth's rotation. They also explained that the geoid is a surface along which the gravity potential is everywhere equal and to which the direction of gravity is always perpendicular when optical instruments containing gravity reference levelling devices are properly adjusted during observation coincides with the direction of gravity and are therefore perpendicular to the geoid. The angle between the plumb line which is perpendicular to the geoid (the vertical) and the perpendicular to the ellipsoid (the ellipsoidal normal) is defined as the deflection of the vertical. Civil engineers use the geoid as the reference surface for elevations while oceanographers use it for studies of ocean circulation, currents and tides. It is also valuable to geophysicists for displacement studies, geophysical interpretation of the Earth's crust, and prospecting (Borge, 2013). 
The GNSS ellipsoidal height is a geometric height which is obtained with reference to the ellipsoid. The ellipsoidal height is not suitable for engineering work as it is not a practical height determined with respect to the geoid. Nowadays, most geodetic observations are carried out with GNSS receivers. The spirit levelling, on the other hand, is time-consuming and applying it over long distances may reduce the reliability of the measurements. But there is a relation, as well as a link between the ellipsoidal height and the orthometric height. The link between the ellipsoidal and the orthometric heights is the geoid height. In other words, if the geoid and the ellipsoidal heights of a point are known, the orthometric height of the point is computed using the relation given by Eteje et al. (2018) and Oluyori et al. (2018) as:

$$
\mathrm{h}=\mathrm{H}+\mathrm{N}
$$

Where,

$\mathrm{h}=$ Ellipsoidal height; $\mathrm{H}=$ Orthometric height; $\mathrm{N}=$ Geoid height

The relationship between the heights is further explained using the three reference surfaces (the ellipsoid, the geoid and the earth surface). The ellipsoidal height is determined with respect to the reference ellipsoid; the orthometric height is obtained with respect to the geoid while the observations are carried out on the earth surface. The ellipsoidal height is the vertical distance measured from the surface of the ellipsoid along the normal to the observation point on the earth surface while the orthometric height is the vertical distance measured from the geoid along the vertical, as well as the plumbline direction to the observation point on the earth surface. Figure 1 shows the relationship between the three reference surfaces, as well as the ellipsoidal, orthometric and the geoid heights (Eteje et al., 2018)



Fig. 1: Relationship between Orthometric, Geoid and Ellipsoidal Heights

Source: Eteje et al. (2018)

The geoid can be determined using various methods such as the gravimetric, geometric, Astro-geodetic, transformation and gravimetric-geometric methods amongst others.
The gravimetric method can be carried out by the wellknown Stokes-integral, equation (2) and the use of accurately determined absolute gravity data (Heiskanen and Moritz, 1967, Eteje, 2015 and Eteje et al., 2018).

$$
N=\frac{R}{4 \pi \gamma} \iint_{\sigma} \Delta g S(\psi) d \sigma
$$

Where $N$ is geoid undulation, $\Delta g$ is gravity anomaly, $S(\psi)$ is stokes function, $\gamma$ is normal gravity on the reference ellipsoid and $R$ is mean radius of the earth. The geometric method is to use the known "geoid heights" at some points, which are derived from co-located GNSSdetermined heights and levelled heights to interpolate the geoid heights at other points (Chen, and Luo, 2004). The interpolation of the geoid heights at any other point involves the use of interpolation models such as bicubic model and other models like multiquadratic model, etc. In Astro-geodetic method of geoid determination, the geoid heights of points are determined with reference to a geodetic (reference) station whose geoid height is known. The geoid heights differences between points are determined using the components of deflection of the gravity vector which can be obtained by carrying out astronomical and geodetic observations. The astronomical observation is carried out to determine the astronomical coordinates (astronomical latitude, $\Phi$ and astronomical longitude, $\Lambda$ ) by observing stars. The geodetic observation is used to determine the geodetic latitude, $\varphi$, geodetic longitude, $\lambda$ and ellipsoidal heights, $h$ as well as the azimuths, $\alpha$ and geodetic distances, $\ell$ between network points. Using the astronomical and geodetic coordinates, the components of deflection of the gravity vector can be computed. The transformation method involves the use of the well-known Euclidean similarity transformation model which is used to convert Cartesian coordinates between two geodetic reference frames that generally differ in terms of three translation parameters (tx, ty, tz), three orientation parameters $(\varepsilon x, \varepsilon y, \varepsilon z)$ and a factor of uniform spatial scale change $(\delta s)$ (Eteje et al., 2018).

The gravimetric-geometric method has to do with the use of gravimetrically and geometrically obtained data. That is the combination of the gravimetric and the geometric methods. Here, the geoid heights of selected points are determined with the gravimetric method and a geometric surface is fitted to the gravimetric geoid heights to enable the interpolation of geoid heights of points of interest. Usually, two or more geometric surfaces are fitted to the geoid heights of the points and the Root Mean Square Error (RMSE), as well as the standard error of each of the models, is computed and compared to obtain the 
most suitable model for application in the study area. The fitting of the geometric surfaces to the gravimetric geoid heights requires the computation of the model parameters, as well as coefficients using the least squares technique. The computed model parameters and the coordinates of the points are used to develop a program for the implementation of the model in the study area. The RMSE and as well as the reliabilities of the models are obtained by comparing the results from physical measurements carried out on some selected points with their corresponding results from the determined geoid models.

Benin City, Nigeria is the capital of Edo State. It is a developing area where massive roads constructions are presently ongoing. As stated earlier, most observations are being carried out using GNSS receivers. Some of the preliminary surveys used for the design of the roads were carried out using Real-Time Kinematic GNSS observation technique. The heights obtained from the observations were ellipsoidal heights and they were used without converting them to orthometric heights. This is because there has not been a local geoid model of Benin City, Nigeria. Orthometric heights are required in engineering constructions to decide on suitable gradients to direct the flow of water at various levels of proposed constructions.
With orthometric height water can flow from one point to another while with ellipsoidal height, it is not possible. Today, the Benin City, Nigeria is facing a serious flood problem. Several attempts have been made to solve this problem but there has not been headway as the height differences between points relative to the geoid as the mean sea level has not been properly established. This study determines and compares three gravimetricgeometric geoid models to decide on the best local geoid model of Benin City, Nigeria.

\subsection{The Study Area}

Benin City, Nigeria is a City approximately 40 kilometres north of the Benin River. The City is also linked by roads to Asaba, Sapele, Siluko, Okene, and Ubiaja and is served by air and the Niger River delta ports of Koko and Sapele. The City is made up of three Local Government Areas, Oredo LGA, Ikpoba Okha LGA and Egor LGA. It has a total population of 1,749,316 according to 2019 NPC projection. It covers a total area of about $1,204 \mathrm{~km}^{2}$. Benin City is bounded by UTM zone 31 coordinates $660000 \mathrm{mN}$ and $712500 \mathrm{mN}$, and $770000 \mathrm{mE}$ and $815000 \mathrm{mE}$. Figures $2 \mathrm{a}$ and $\mathrm{b}$ show the maps of the study area.

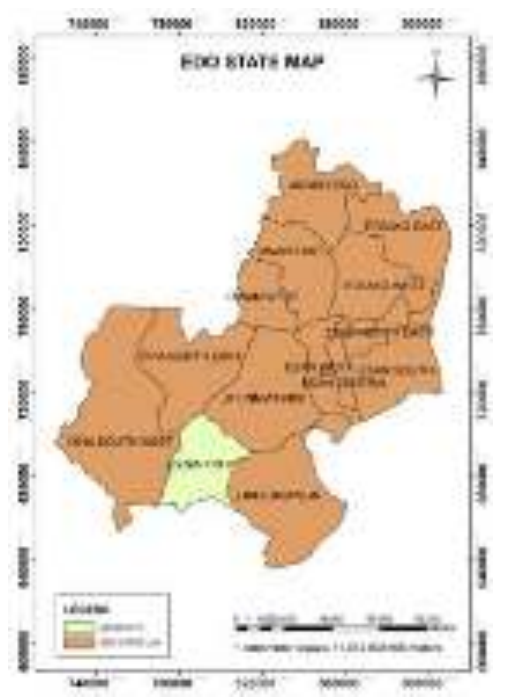

Fig. 2a: Map of Edo State

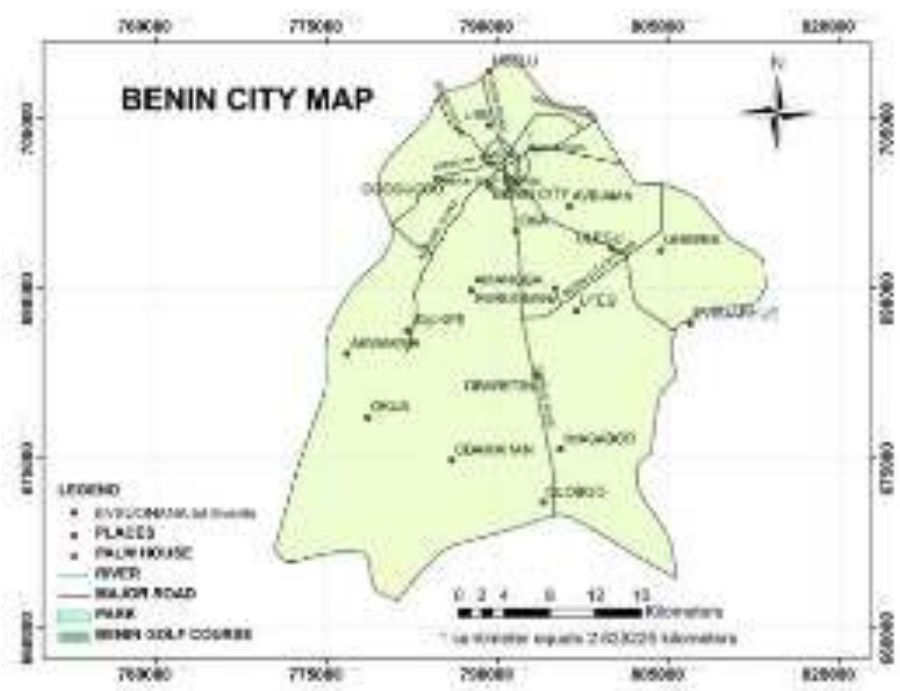

Fig. 2b: Map of Benin City

Source: Ministry of Lands and Surveys, Benin City

\subsection{Normal Gravity Computation}

The normal, as well as the latitude gravity, is computed on a specified ellipsoid. Eteje et al. (2018) gave the model for the computation of the theoretical gravity on the Clarke 1880 ellipsoid as 


$$
g_{\text {TClarkel } 880(B)}=9.78051938\left(\begin{array}{l}
1+0.005247466 \sin ^{2} \varphi \\
-0.0000087985 \sin ^{2} 2 \varphi
\end{array}\right) \mathrm{ms}^{-2}
$$

Where,

$g_{\text {Tlarkel } 880}=$ Theoretical gravity on the Clarke

$\varphi=$ Station latitude

\subsection{Gravity Anomaly}

The gravity anomaly, $\Delta g$, is the difference between the observed gravity value $(g)$ reduced to the geoid, and a normal, or theoretical, computed gravity value $\left(\gamma_{o}\right)$ at the mean earth ellipsoid, where, the actual gravity potential on the geoid equal the normal gravity potential at the ellipsoid, at the projection of the same terrain point on the geoid and the ellipsoid respectively, that is (Dawod, 1998 and Eteje et al., 2019)

$$
\Delta g=g-\gamma_{o}
$$

Considering the nature of the topography of the earth surface, which is irregular in shape, there are two basic types of gravity anomalies (free air and Bouguer anomalies). In this study, it was only the free air correction that was applied. That is free air gravity anomalies that were used.

\subsection{Free Air Correction}

This is the first step for reducing topography effects. It simply corrects for the change in the elevation of the gravity meter, considering only air (hence a free-air) being between the meter and selected datum. According

$$
N=\frac{r \Delta g}{8 \gamma}\left(\begin{array}{l}
-6 \sin ^{2} \psi_{o} \ln \left\{\sin \left(\frac{\psi_{o}}{2}\right)+\sin ^{2}\left(\frac{\psi_{o}}{2}\right)\right\}+16 \sin \left(\frac{\psi_{o}}{2}\right)+12 \sin ^{2}\left(\frac{\psi_{o}}{2}\right) \\
-24 \sin ^{3}\left(\frac{\psi_{o}}{2}\right)-12 \sin ^{4}\left(\frac{\psi_{o}}{2}\right)-4 \cos \psi_{o}+5 \cos 2 \psi_{o}-1
\end{array}\right)
$$

Where $N$ is the geoidal height of individual point, $\psi_{o}$ is the surface spherical radius, $\gamma$ is the theoretical as well as normal gravity, $\Delta g$ is the gravity anomaly and $r=R$ is the mean radius of the earth.

\subsection{Computation of Surface Spherical Radius, $\psi_{o}$}

The surface spherical radius, $\psi_{o}$ is computed as (Shrivastava et al., 2015)

$$
\cos \psi=\sin \varphi \sin \varphi^{1}+\cos \varphi \cos \varphi^{1} \cos \left(\lambda^{1}-\lambda\right)
$$

Where,

$$
\begin{aligned}
& \varphi=\text { Mean latitude of the points } \\
& \varphi^{1}=\text { Latitude of individual point } \\
& \lambda=\text { Mean longitude of the points }
\end{aligned}
$$

1880 ellipsoid

to Aziz et al. (2010), this correction is added to the observed gravity because the increased radial distance of the station from the centre of the Earth results in a lower observed gravity value than if the station were at the local datum. The formula to calculate the magnitude of the reduction in practice is given by Eteje et al. (2019) as

$$
\begin{aligned}
g_{F A} & =-\frac{2 g}{r} H_{s}=-308.6 H \mu G a l \\
& =-0.3086 \mathrm{HmGal}
\end{aligned}
$$

Where,

$$
\begin{aligned}
& H=\text { Station orthometric height in metres } \\
& g=\text { Mean value of gravity }(980500 \mathrm{mGal}) \\
& r=\text { Mean radius of the Earth }
\end{aligned}
$$

\subsection{Integration of Stokes's Formula}

According to Eteje et al. (2018), using the modified Stokes integral given in equation (2), the geoid heights of points are computed if their gravity anomalies and geographic coordinates are known. Featherstone and Olliver (1997) gave the integration of equation (2) as

$$
\lambda^{1}=\text { Longitude of individual point }
$$

\subsection{Computation of Combined Topographic Effect}

To obtain a precise geoid height of a point, the combined topographic effect is calculated and applied to the computed geoid height of the point. The formula for the computation of the combined topographic effect, $\delta N_{\text {Comb }}^{\text {Topo }}$ is given as (Sjöberg, 2000 and KuczynskaSiehien et al., 2016):

$$
\delta N_{\text {Comb }}^{\text {Topo }}=-\frac{2 \pi G \rho}{\gamma}\left[H^{2}+\frac{2}{3 R} H^{2}\right]
$$

where $G$ is the earth gravitational constant, $\rho$ is density, $R$ is the mean radius of the earth and $H$ is the orthometric height of observation point which can be obtained from the DTM of the area. 


\subsection{Geometric Geoid Surfaces}

According to Eteje et al. (2018), geometric geoid surfaces are mathematical interpolation surfaces fitted to geoid heights to enable geoid heights of new points to be determined using variable such as geographic or rectangular coordinates of the points. These surfaces include plane surface, bi-linear surface, second degree surface, third degree polynomial and fifth degree polynomial. Eteje et al. (2018) further explained that the surface to be adopted as well as the degree and order of the polynomial depends on the size of the study area and the variation of the geoid heights. For a small area, the plane surface is used, for a relatively large area, the second and third order polynomial surfaces are used.

\subsection{Plane Surface}

The plane surface as given by Odumosu et al (2016) is $N=(h-H)=N_{o}+N_{1} e+N_{2} n+\delta_{N}$

The least squares solution to equation (9) can be further mathematically expressed as (Odumosu et al, 2016):

$$
\begin{aligned}
& (h-H)=N_{o}+N_{1} e+N_{2} n \\
& (H)=h-N_{o}-N_{1} e-N_{2} n \\
& (h-H)=\left(\begin{array}{lll}
1 & e & n
\end{array}\right)\left(\begin{array}{c}
N_{o} \\
N_{1} \\
N_{2}
\end{array}\right)
\end{aligned}
$$$$
N=a_{00}+a_{10} X+a_{01} Y+a_{20} X^{2}+a_{11} X Y+a_{02} Y^{2}+a_{30} X^{3}+a_{21} X^{2} Y+a_{12} X Y^{2}+a_{03} Y^{3}
$$

Where $\mathrm{X}$ is the required parameters $=\left(\begin{array}{c}N_{O} \\ N_{1} \\ N_{2}\end{array}\right), e$ and $n$ are respectively easting and northing coordinates of the selected points.

\subsection{Polynomial Surface}

The polynomial surface for local geoid heights interpolation given by Kirici and Sisman (2017) and Oluyori et al. (2018) is

$$
N_{(x, y)}=\sum_{i=0}^{m} \sum_{\substack{j=k-i \\ i=0}}^{k} a_{i j} x^{i} y^{j}
$$

Where

$$
\begin{aligned}
& a_{i j}=\text { Polynomial coefficients } \\
& m=\text { Degree of polynomial } \\
& x, y=\text { Plan coordinates of points }
\end{aligned}
$$

In applying the polynomial, the degree should be chosen and the polynomial should be formed for the chosen degree. Kirici and Sisman (2017) gave the third degree polynomial as

Also, Sanlioglu et al. (2009) gave the second degree polynomial, Multi-quadratic model as:

$$
N=a_{0}+a_{1} X+a_{2} Y+a_{3} X^{2}+a_{4} Y^{2}+a_{5} X Y+a_{6} X^{2} Y+a_{7} X Y^{2}+a_{8} X^{2} Y^{2}
$$

Where,

$$
\begin{aligned}
& Y=A B S\left(y-y_{o}\right) \\
& X=A B S\left(x-x_{o}\right) \\
& y=\text { Northing coordinate of observed station } \\
& x=\text { Easting coordinate of observed station } \\
& y_{o}=\text { Northing coordinate of the origin (average of } \\
& \text { the northing coordinates) } \\
& x_{o}=\text { Easting coordinate of the origin (average of the } \\
& \text { easting coordinates) }
\end{aligned}
$$

\subsection{Observation Equation Method of Least Squares Adjustment}

The fitting of the polynomial interpolation surface to a set of geoid heights requires the model parameters (variable coefficients) to be computed. The computation of these coefficients is done by observation equation method of least squares adjustment technique. The functional relationship between adjusted observations and the adjusted parameters as given by Eteje and Oduyebo (2018) is:

$$
L_{a}=F\left(X_{a}\right)
$$

Where $L_{a}=$ adjusted observations and $X_{a}=$ adjusted parameters. Equation (16) is a linear function and the general observation equation model was obtained. The system of observation equations is presented by matrix notation as (Ono et al., 2018):

$V=A X-L$

Where,

$$
\begin{aligned}
& A=\text { Design Matrix, } \\
& X=\text { Vector of Unknowns } \\
& L=\text { Observation Matrix. } \\
& V=\text { Residual Matrix }
\end{aligned}
$$

The residual, $V$ which is the difference between the estimate and the observed is usually useful when applying least squares adjustment technique for the determination of geoid heights interpolation model parameters since it is 
equal to the difference between the model geoid heights and the computed geoid heights from GNSS observations and spirit levelling of the points. So, it can be used as a check. The unknown/model parameter is computed as (Oluyori et al., 2019)

$$
X=\left(A^{T} A\right)^{-1} A^{T} L
$$

Where,

$$
\left(A^{T} A\right)^{-1}=\text { Inverse of the normal matrix }
$$

The step by step procedures for the computation of the polynomial interpolation model Coefficients $\left(a_{m n}\right)$ of the variables $(x, y)$ are detailed in Eteje and Oduyebo (2018).

\subsection{Accuracy of the Model}

The accuracy of the gravimetric-geometric geoid models is obtained using the Root Mean Square Error, RMSE index. To compute the accuracy of the model, the geoid heights of the selected points from the geoid model are compared with their corresponding gravimetric geoid heights to obtain the geoid height residuals. The geoid height residuals and the total number of the selected points are used for the computation of the RMSE, as well as the accuracy of the model. The Root Mean Square Error, RMSE index for the computation of the gravimetricgeometric geoid model accuracy as given by Yilmaz and Kozlu (2018) is

$$
R M S E= \pm \sqrt{\frac{1}{n} \sum_{i=1}^{n}\left(\delta N_{\text {Residual }}\right)^{2}}
$$

Where,

$$
\begin{aligned}
& \left.\delta N_{\text {Residual }}=N_{\text {Computed }}-N_{\text {Model }}\right) \\
& N_{\text {Computed }}=\text { Gravimetric Geoid Height } \\
& N_{\text {Model }}=\text { Gravimetric-Geometric Geoid Height } \\
& \mathrm{n}=\text { Number of Points }
\end{aligned}
$$

\section{METHODOLOGY}

The methodology was divided into data acquisition, data processing and results presentation and analysis. Figure 3 shows the flow chart of the adopted methodology.



Fig 3: Flow Chart of the Adopted Methodology

\subsection{Data Acquisition}

A total of 49 points were used in the study. The points included two primary control stations (XSU 92 and XSU 100 were respectively located in Edo College and School of Nursing premises). The points were selected along the major roads of the City (See Figure 4). GNSS observation was carried out using CHC 900 dual-frequency GNSS receivers to obtain the coordinates and ellipsoidal heights of the points. The observations were carried out relative to control station XSU 92 using the static method of GNSS observation (See Figures 5 and 6). 


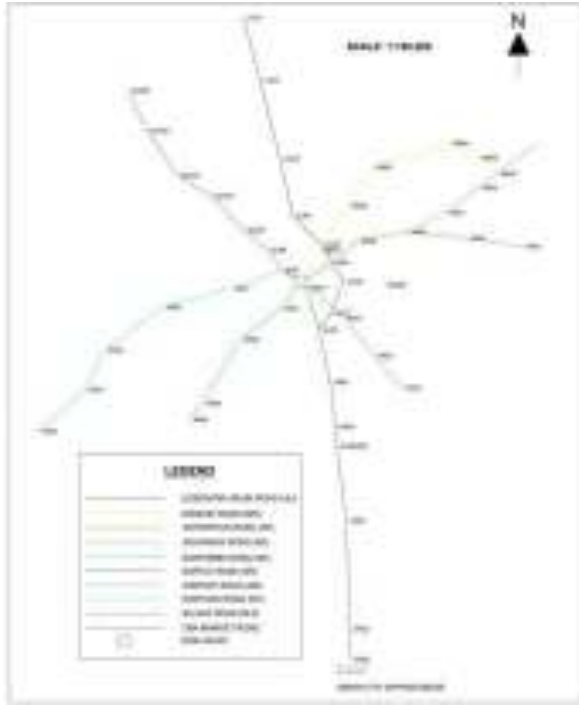

Fig 4: Selected GPS and Gravity Points



Fig. 5: Base Receiver at Control Station XSU92

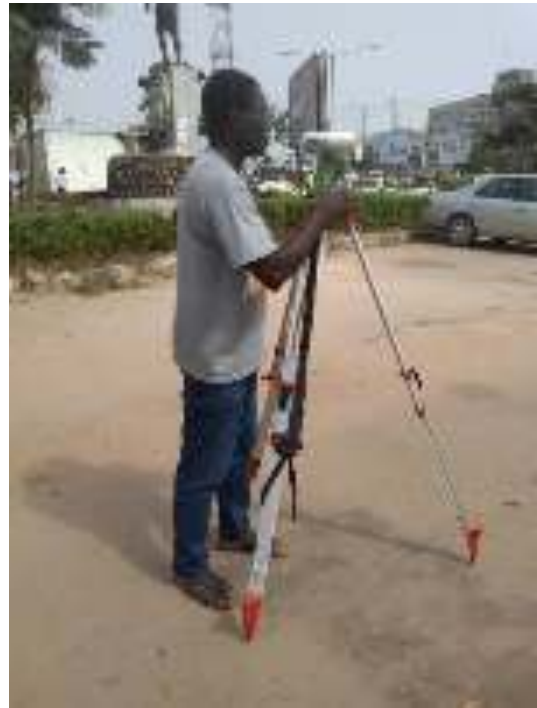

Fig. 6: Rover Receiver at One of the Points (RR01) at Ring Road
The selected points were observed with a gravimeter (SCINTREX CG-5 Autograv Gravimeter) to obtain their absolute gravity values. The observation was carried out by an expert, a Geophysicist from Mountain Top University, Ibafo, Ogun State. The gravity observation of

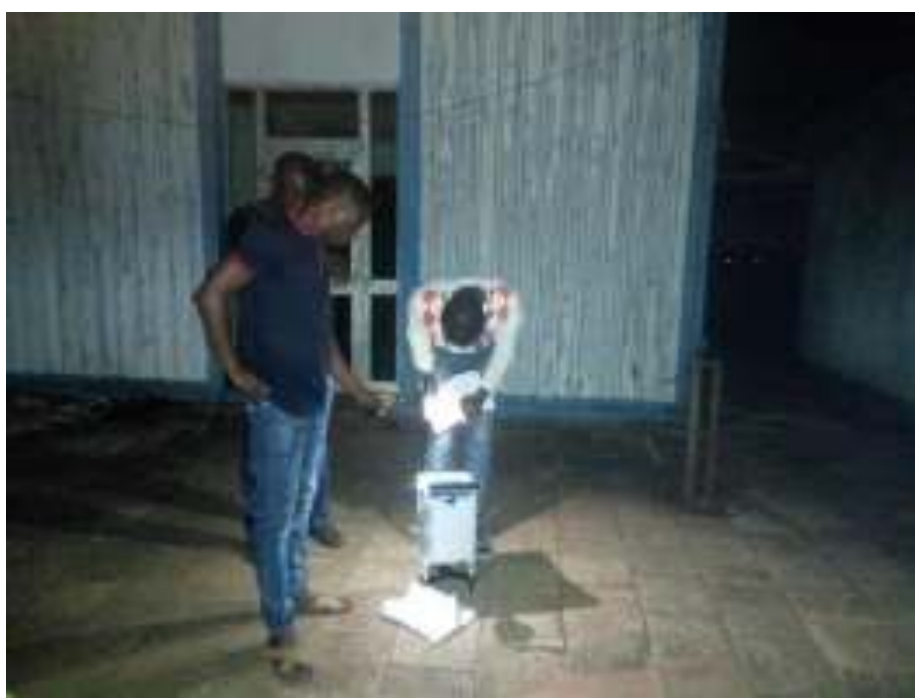

Fig. 7: Gravimeter Set over Reference Station at Benin City Airport the points was carried out in seven different loops relative to a point whose absolute gravity value was known which was located within the Benin City Airport premises (See Figures 7 and 8).

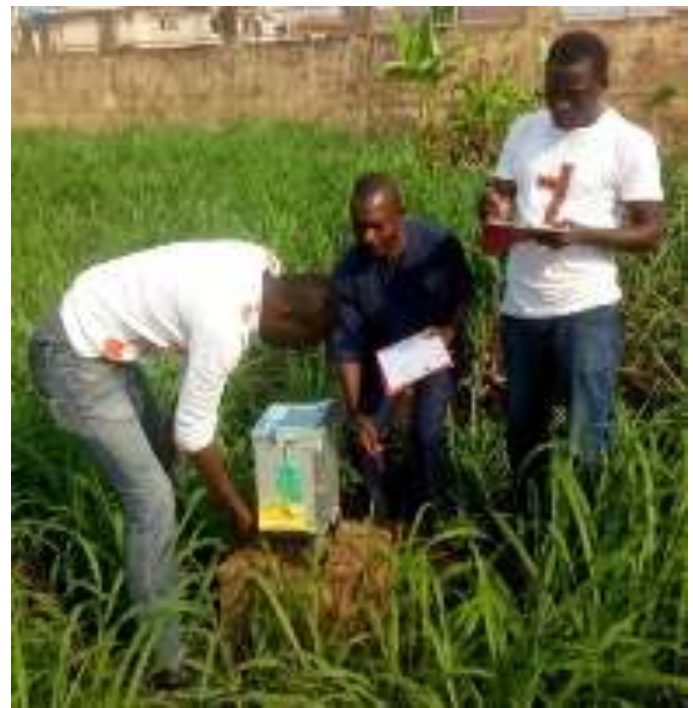

Fig. 8: Gravimeter at Control Station XSU92

\subsection{Data Processing}

The GNSS observations were respectively downloaded and processed with HcLoader and Compass Postprocessing software to obtain the positions and the ellipsoidal heights of the points. The geographic and rectangular coordinates, as well as the ellipsoidal heights of the points, were processed in Minna datum. The gravity observations of the points were processed by the expert who carried out the observations to obtain their absolute gravity values. All the necessary corrections such as drift correction, etc were applied during the processing. The theoretical gravity values of the points were computed on the local (Minna) datum ellipsoid (Clarke 1880 ellipsoid) using the latitude coordinates of the points, as well as equation (3). The gravity anomalies of the points were computed by finding the differences between the absolute gravity values of the points and their corresponding theoretical gravity values, as well as using equation (4). The computation of the free air correction requires the application of the orthometric heights of the points. And these were obtained by interpolation using the orthometric heights and the absolute gravity values of the two primary 
control stations (XSU 100 and XSU 96). The orthometric heights of the points were interpolated as there was no Digital Terrain Model (DTM) of the study area. The free air correction was applied to the computed gravity anomalies of the points using equation (5). The free air and the Bouguer gravity anomalies of the points were computed but the free air gravity anomalies were used in the study. This is because the geoid heights of the two primary control stations obtained from their known orthometric and ellipsoidal heights approximated the geoid heights of the stations computed using the free-air gravity anomalies, as well as equation (6). The gravimetric geoid heights of the points were computed with the geographic coordinates, free air gravity anomalies and the theoretical gravity values of the points using equation (6). The computation of the gravimetric geoid heights of the points required the application of the spherical radius and it was computed using equation (7). The computed gravimetric geoid heights of the points using equation (6) were cogeoid heights. To obtain precise gravimetric geoid heights of the points, the combined topographic effect has to be computed and applied to the co-geoid heights. The combined topographic effect was computed using equation (8). To obtain the best gravimetric-geometric geoid model of Benin City, three geometric geoid surfaces (plane surface, equation (9), second degree surface, equation (10) and third degree surface, equation (11)) were fitted to the gravimetric geoid heights of the points. The fitting of the geometric geoid surfaces to gravimetric geoid heights of the points requires the computation of the model parameters using the least squares adjustment technique. The models' parameters were computed using equation (18). Microsoft Excel programs were developed with the computed models' parameters. The RMSE, as well as the accuracy of the models, were respectively computed with equations (19).

\section{RESULTS PRESENTATION AND ANALYSIS}

\subsection{Analysis of the GNSS Observation Results}

The DGPS observation was carried out to obtain the coordinates and the ellipsoidal heights of the selected points. The DGPS observations were processed using Compass post-processing software. From the processing of the DGPS observations results, it was seen that the processed observations passed both the Network Adjustment Test and the $\chi$-Square (Chi-square) Test. This implies that the normal matrix generated was a regular one and inverted accordingly for the calculation of residuals.

\subsection{Analysis of the Gravimetric-Geometric Geoid Models}

Table 1 presents the gravimetric geoid heights; the three gravimetric-geometric geoid models (plane, second degree and third degree surfaces/models) heights and their respective RMSE while Figure10 shows the plot of the RMSE of the three gravimetric-geometric geoid models. This was done to determine which of the three gravimetric-geometric geoid models is most suitable for application in the study area. The smaller the RMSE, the better the gravimetric-geometric geoid model. It is seen from Table 1 and Figure 10 that the RMSE of the plane surface, second degree surface, and the third degree surface models are respectively $0.9839 \mathrm{~m}, 0.7126 \mathrm{~m}$ and $0.6746 \mathrm{~m}$ which shows that the third degree gravimetricgeometric geoid model is most suitable for application in the study area. It can also be seen from Table 1 that the minimum and the maximum geoid heights from the third degree surface gravimetric-geometric geoid model are respectively $1.002 \mathrm{~m}$ and $3.760 \mathrm{~m}$. This shows that geoid heights can be interpolated with the chosen (third degree surface gravimetric-geometric) geoid model within the range of $1.002 \mathrm{~m}$ to $3.760 \mathrm{~m}$ in Benin City, Nigeria.

Table 1: Gravimetric Geoid Heights, the Three Gravimetric-geometric Geoid Models heights and their Absolute Differences between the Gravimetric Geoid heights

\begin{tabular}{|c|c|c|c|c|c|c|c|}
\hline \multirow[b]{2}{*}{ POINT } & \multirow[b]{2}{*}{$\begin{array}{l}\text { GRAVIMETRIC } \\
\text { GEOID } \\
\text { HEIGHT (m) (A) }\end{array}$} & \multicolumn{3}{|c|}{ MODEL GEOID HEIGHT } & \multirow{2}{*}{$\begin{array}{c}\text { DIFF. B/W } \\
(A) \&(B) \\
(\mathbf{m}) \\
\text { SQUARED }\end{array}$} & \multirow{2}{*}{$\begin{array}{c}\text { DIFF. B/W } \\
(\mathbf{A}) \&(\mathbf{C}) \\
(\mathbf{m}) \\
\text { SQUARED }\end{array}$} & \multirow{2}{*}{$\begin{array}{l}\text { DIFF. B/W } \\
\text { (A) \& (D) } \\
\text { (m) } \\
\text { SQUARED }\end{array}$} \\
\hline & & $\begin{array}{l}\text { PLANE } \\
\text { SURFACE } \\
\text { (m) (B) }\end{array}$ & $\begin{array}{c}\text { SECOND } \\
\text { DEGREE } \\
(\mathbf{m})(\mathbf{C})\end{array}$ & $\begin{array}{l}\text { THIRD } \\
\text { DEGREE } \\
\text { (m) (D) }\end{array}$ & & & \\
\hline XSU92 & 2.086 & 2.386 & 0.749 & 1.072 & 0.0900 & 1.7876 & 1.0282 \\
\hline RR01 & 2.420 & 2.069 & 1.456 & 2.257 & 0.1232 & 0.9293 & 0.0266 \\
\hline SR01 & 1.588 & 1.989 & 1.607 & 2.275 & 0.1608 & 0.0004 & 0.4720 \\
\hline SR02 & 1.978 & 1.927 & 1.791 & 2.209 & 0.0026 & 0.0350 & 0.0534 \\
\hline SR04 & 2.520 & 1.799 & 2.504 & 3.260 & 0.5198 & 0.0003 & 0.5476 \\
\hline SR05 & 2.802 & 1.614 & 3.266 & 3.445 & 1.4113 & 0.2153 & 0.4134 \\
\hline SR06 & 3.266 & 1.560 & 3.442 & 2.961 & 2.9104 & 0.0310 & 0.0930 \\
\hline XSU100 & 2.098 & 1.897 & 1.872 & 2.214 & 0.0404 & 0.0511 & 0.0135 \\
\hline
\end{tabular}




\begin{tabular}{|c|c|c|c|c|c|c|c|}
\hline AR01 & 0.685 & 1.922 & 1.239 & 1.240 & 1.5302 & 0.3069 & 0.3080 \\
\hline AR02 & 0.720 & 1.698 & 1.343 & 1.082 & 0.9565 & 0.3881 & 0.1310 \\
\hline AR03 & 1.436 & 1.425 & 2.452 & 2.233 & 0.0001 & 1.0323 & 0.6352 \\
\hline AR04 & 1.439 & 1.342 & 2.827 & 2.658 & 0.0094 & 1.9265 & 1.4860 \\
\hline UU01 & 4.658 & 2.307 & 3.880 & 3.667 & 5.5272 & 0.6053 & 0.9821 \\
\hline UU02 & 3.498 & 2.259 & 2.527 & 2.905 & 1.5351 & 0.9428 & 0.3516 \\
\hline UU03 & 1.981 & 2.197 & 1.680 & 1.761 & 0.0467 & 0.0906 & 0.0484 \\
\hline UU04 & 1.276 & 2.142 & 1.538 & 1.407 & 0.7500 & 0.0686 & 0.0172 \\
\hline UU05 & 1.346 & 2.208 & 1.429 & 1.330 & 0.7430 & 0.0069 & 0.0003 \\
\hline UU06 & 1.489 & 2.228 & 0.940 & 1.175 & 0.5461 & 0.3014 & 0.0986 \\
\hline UU07 & 1.329 & 2.122 & 1.253 & 1.197 & 0.6288 & 0.0058 & 0.0174 \\
\hline UU08 & 1.263 & 2.039 & 1.469 & 1.374 & 0.6022 & 0.0424 & 0.0123 \\
\hline AD01 & 2.986 & 2.777 & 2.171 & 2.299 & 0.0437 & 0.6642 & 0.4720 \\
\hline AD02 & 4.019 & 2.956 & 2.839 & 3.041 & 1.1300 & 1.3924 & 0.9565 \\
\hline AD03 & 4.420 & 3.059 & 3.103 & 3.321 & 1.8523 & 1.7345 & 1.2078 \\
\hline AK01 & 1.376 & 2.217 & 1.211 & 1.211 & 0.7073 & 0.0272 & 0.0272 \\
\hline AK02 & 1.473 & 2.360 & 1.242 & 1.002 & 0.7868 & 0.0534 & 0.2218 \\
\hline AK03 & 2.252 & 2.583 & 1.503 & 1.463 & 0.1096 & 0.5610 & 0.6225 \\
\hline AK04 & 3.101 & 2.816 & 2.240 & 2.485 & 0.0812 & 0.7413 & 0.3795 \\
\hline AK05 & 3.954 & 3.026 & 3.615 & 3.283 & 0.8612 & 0.1149 & 0.4502 \\
\hline MR01 & 1.300 & 2.191 & 1.415 & 1.372 & 0.7939 & 0.0132 & 0.0052 \\
\hline MR02 & 1.488 & 2.386 & 1.560 & 1.220 & 0.8064 & 0.0052 & 0.0718 \\
\hline MR03 & 1.614 & 2.561 & 2.115 & 1.786 & 0.8968 & 0.2510 & 0.0296 \\
\hline MR04 & 4.037 & 2.919 & 3.119 & 3.146 & 1.2499 & 0.8427 & 0.7939 \\
\hline MR05 & 4.313 & 3.010 & 3.069 & 3.302 & 1.6978 & 1.5475 & 1.0221 \\
\hline SK01 & 1.500 & 2.163 & 1.193 & 1.043 & 0.4396 & 0.0942 & 0.2088 \\
\hline SK02 & 2.035 & 2.219 & 1.542 & 1.233 & 0.0339 & 0.2430 & 0.6432 \\
\hline SK03 & 2.379 & 2.275 & 2.161 & 1.931 & 0.0108 & 0.0475 & 0.2007 \\
\hline EKS & 0.665 & 2.001 & 1.204 & 1.325 & 1.7849 & 0.2905 & 0.4356 \\
\hline SLK0 & 0.668 & 1.978 & 1.222 & 1.051 & 1.7161 & 0.3069 & 0.1467 \\
\hline SLK01 & 0.781 & 1.915 & 1.345 & 1.067 & 1.2860 & 0.3181 & 0.0818 \\
\hline SLK02 & 1.326 & 1.846 & 1.942 & 1.716 & 0.2704 & 0.3795 & 0.1521 \\
\hline SLK03 & 1.736 & 1.745 & 2.537 & 2.506 & 0.0001 & 0.6416 & 0.5929 \\
\hline SLK04 & 2.688 & 1.702 & 3.314 & 3.431 & 0.9722 & 0.3919 & 0.5520 \\
\hline SLK05 & 3.357 & 1.699 & 3.555 & 3.760 & 2.7490 & 0.0392 & 0.1624 \\
\hline EK01 & 0.078 & 1.757 & 0.776 & 1.043 & 2.8190 & 0.4872 & 0.9312 \\
\hline EK02 & 0.983 & 1.439 & 1.643 & 2.010 & 0.2079 & 0.4356 & 1.0547 \\
\hline EK03 & 1.729 & 1.124 & 3.160 & 3.156 & 0.3660 & 2.0478 & 2.0363 \\
\hline EK04 & 2.001 & 0.969 & 3.389 & 3.344 & 1.0650 & 1.9265 & 1.8036 \\
\hline EK05 & 2.516 & 0.701 & 2.480 & 2.247 & 3.2942 & 0.0013 & 0.0724 \\
\hline AIRPORT & 0.578 & 1.705 & 1.298 & 1.058 & 1.2701 & 0.5184 & 0.2304 \\
\hline \multicolumn{8}{|c|}{\begin{tabular}{c|c|c|c|} 
RMSE $=$ & $\mathbf{0 . 9 8 3 9}$ & $\mathbf{0 . 7 1 2 6}$ & $\mathbf{0 . 6 7 4 6}$ \\
\end{tabular}} \\
\hline
\end{tabular}




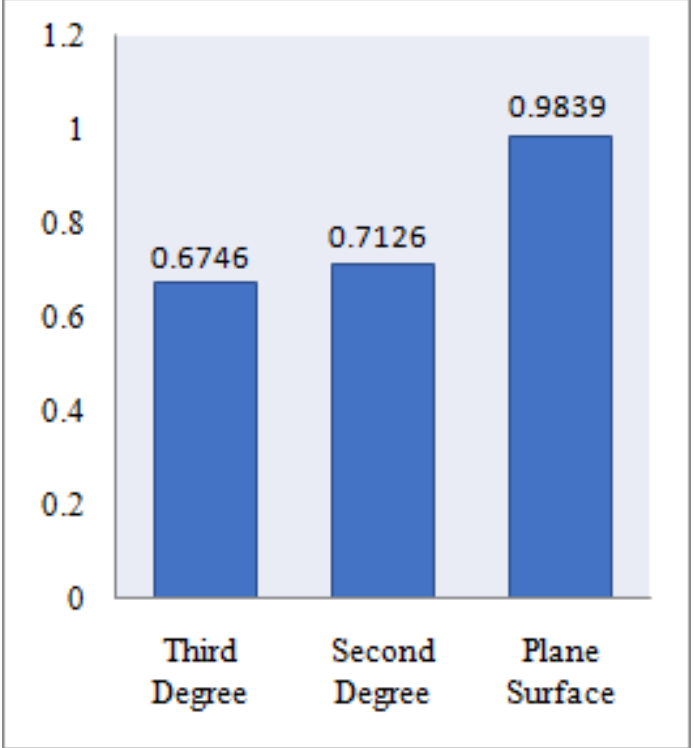

Fig 10: Plot of RMSE of the three Gravimetric-Geometric Geoid Models

Figures 11 a to $11 \mathrm{~d}$ respectively show the surface plots of the gravimetric, third degree surface gravimetricgeometric, second degree surface gravimetric-geometric and the plane surface gravimetric-geometric geoid heights of the selected points. This was done to present graphically the shape of the gravimetric geoid heights and those of the three gravimetric-geometric geoid models to determine which of the three gravimetric-geometric geoid models shape is most identical with the gravimetric geoid heights shape by comparing the three gravimetricgeometric geoid models shapes with that of the gravimetric heights. Comparing the three gravimetricgeometric geoid models shapes with that of the gravimetric geoid heights also enables the determination of which of the three gravimetric-geometric geoid models is most suitable for application in the study area. It can be seen from Figures 11a to 11d that the shape of the third degree surface gravimetric-geometric geoid model is most identical with that of the gravimetric geoid heights. This also implies that the third degree surface gravimetricgeometric geoid model is most suitable for application in the study area.

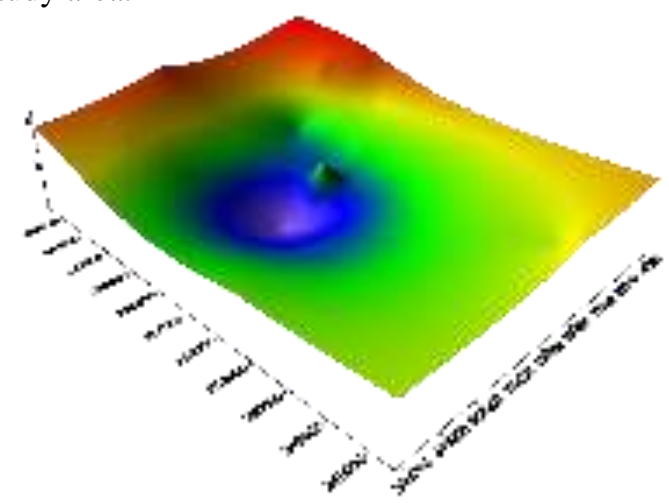

Fig 11a: Surface Plot of Gravimetric Geoid Heights

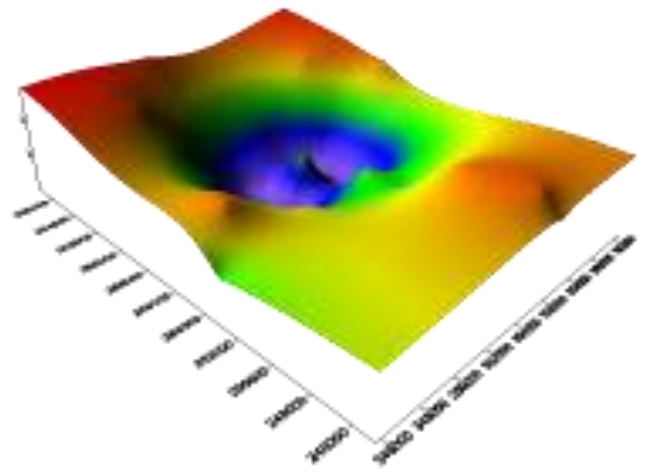

Fig 11b: Surface Plot of Third Degree GravimetricGeometric Model Geoid Heights

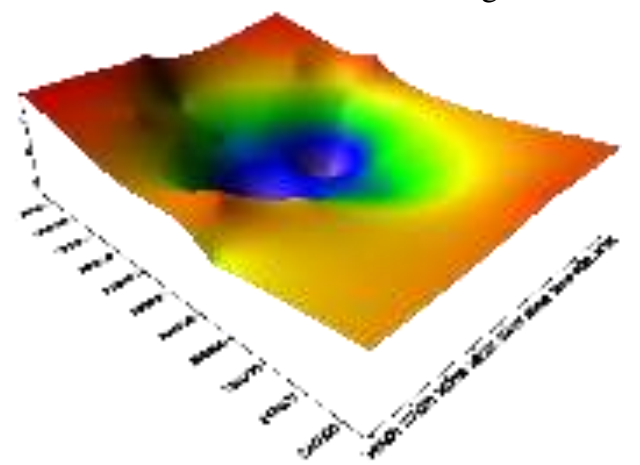

Fig 11c: Surface Plot of Second Degree GravimetricGeometric Model Geoid Heights

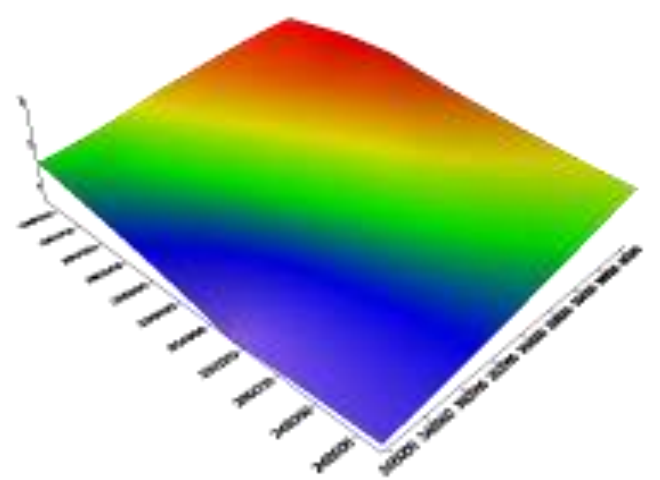

Fig 11d: Plot of Plane Surface Gravimetric-Geometric Model Geoid Heights

\section{CONCLUSIONS AND RECOMMENDATIONS}

1. The study has established the local geoid model of Benin City, Nigeria from the combination of gravimetric and geometric methods of geoid determination.

2. The determined geoid model was termed local geoid model as the absolute gravity values used were obtained from gravimetric observations carried out physically in the study area and as their respective theoretical gravity values were computed on the 
local ellipsoid adopted for geodetic computation in the study area.

3. The gravimetric-geometric geoid models were obtained by fitting three geometric geoid surfaces to the computed gravimetric geoid heights using the least squares technique.

4. The accuracy of the three gravimetric-geometric geoid models was obtained by computing their respective RMSE.

5. The third degree surface gravimetric-geometric geoid model is recommended for application in Benin City, Nigeria as it has the highest accuracy among the three gravimetric-geometric geoid models.

6. A Microsoft Excel program was developed for full implementation of the determined geoid model in the study area.

7. It is recommended that whenever ellipsoidal heights obtained from GNSS observations within Benin City, Nigeria are to be converted to practical, as well as orthometric heights, the determined geoid model should be applied.

8. It is also recommended that the use of assumed, as well as handheld GPS receiver heights for engineering works should be totally abolished as this study has established the local geoid model of Benin City.

\section{REFERENCES}

[1] Aziz, N., Majid, B. and Jörg, E. (2010). Gravity and Magnetic Data Acquisition Over a Segment of the Møre-Trøndelag Fault Complex. NGU Report 2010.049.

[2] Borge, A. (2013). Geoid Determination over Norway Using Global Earth Gravity Models. Published MSc Thesis of the Department of Civil and Transport Engineering, Norwegian University of Science and Technology.

[3] Chen, Y. and Luo, Z. (2004). A Hybrid Method to Determine a Local Geoid Model-Case Study. Earth Planets Space, Vol. 56, Pp419-427.

[4] Dawod, D. M. (1998). A National Gravity Standardization Network for Egypt. Published Ph.D Dissertation of the Department of Surveying Engineering, Shoubra Faculty of Engineering, Zagazig University. https://www.academia.edu/794554/The_egyptian_na tional_gravity_standardization_network_ENGSN97 _. Accessed 20th September 2019.

[5] Eteje, S. O. (2015). Determination of the Local Geoid Model Using the Geometric (GPS/Levelling)
Method for Evboriaria in Benin City, Edo State. Unpublished MSc Thesis of the Department of Surveying and Geoinformatics, Nnamdi Azikiwe University, Awka.

[6] Eteje, S. O. and Oduyebo, F. O. (2018). Local Geometric Geoid Models Parameters and Accuracy Determination Using Least Squares Technique. International Journal of Innovative Research and Development (IJIRD), Vol. 7, No 7, pp 251-257. DOI: 10.24940/ijird/2018/v7/i7/JUL18098.

[7] Eteje, S. O., Oduyebo, O. F. and Olulade, S. A. (2018). Procedure for the Determination of Local Gravimetric-Geometric Geoid Model. International Journal of Advances in Scientific Research and Engineering, Vol. 4, No. 8, pp 206-214. DOI: 10.31695/IJASRE.2018.32858.

[8] Eteje, S. O., Oduyebo, O. F. and Oluyori, P. D. (2019). Modelling Local Gravity Anomalies from Processed Observed Gravity Measurements for Geodetic Applications. International Journal of Scientific Research in Science and Technology, Vol. 6, No. 5, pp 144-162. DOI: 10.32628/IJSRST196515.

[9] Eteje, S. O., Oduyebo, O. F. and Oluyori, P. D. (2019). Relationship between Polynomial Geometric Surfaces Terms and Observation Points Numbers and Effect in the Accuracy of Geometric Geoid Models. International Journal of Environment, Agriculture and Biotechnology (IJEAB), Vol. 4, No. 4, pp 1181-1194. DOI: 10.22161/ijeab.4444.

[10] Eteje, S. O., Oduyebo, O. F. and Ono, M. N. (2019). Derivation of Theoretical Gravity Model on the Clarke 1880 Ellipsoid for Practical Local Geoid Model Determination. Scientific Research Journal (SCIRJ), Vol. 7, No 2, pp 12-19. DOI: 10.31364/SCIRJ/v7.i2.2019.P0219612.

[11] Eteje, S. O., Ono, M. N. and Oduyebo, O. F. (2018). Practical Local Geoid Model Determination for Mean Sea Level Heights of Surveys and Stable Building Projects. IOSR Journal of Environmental Science, Toxicology and Food Technology (IOSRJESTFT), Vol. 12, No. 6, pp 30-37.

[12] Featherstone, W. E. and Olliver, J. G. (1997). A Method to Validate Gravimetric-Geoid Computation Software Based on Stokes's Integral Formula. Journal of Geodesy, Vol. 71, pp 571-576.

[13] Heiskanen, W. A. and Moritz, H. (1967). Physical Geodesy. W. H. Freeman and Company, San Francisco in Eteje, S. O. (2015): Determination of the Local Geoid Model Using the Geometric (GPS/Levelling) Method for Evboriaria in Benin 
City, Edo State. Unpublished MSc Thesis of the Department of Surveying and Geoinformatics, Nnamdi Azikiwe University, Awka.

[14] Kirici, U. and Sisman, Y. (2017). The Comparison of the Adjustment Methods in Geoid Determination Method. FIG Working Week, Helsinki, Finland.

[15] Kuczynska-Siehien, J., Lyszkowicz, A. and Birylo, M. (2016). Geoid Determination for the Area of Poland by the Least Squares Modification of Stokes' Formula. Acta Geodyn. Geomater, Vol. 13, No. 1, Pp 19-26.

[16] Musset, A. E. and Khan, M. A., (2000). Looking into the Earth. Cambridge University Press, New York, USA.

[17] Odumosu, J. O., Kelly, K. M., Omogunloye, O. G., Adejare, Q. A., Adeleke, O. O. and Olaniyi, A. M. (2016). Empirical Geoid Modelling Using Classical Gravimetric Method. FIG Working Week, Christchurch, New Zealand.

[18] Oluyori, P. D., Ono, M. N. and Eteje, S. O. (2018). Comparison of Two Polynomial Geoid Models of GNSS/Levelling Geoid Development for Orthometric Heights in FCT, Abuja. International Journal of Engineering Research and Advanced Technology (IJERAT), Vol. 4, No. 10, pp 1-9. DOI: 10.31695/IJERAT.2018.3330.

[19] Oluyori, P. D., Ono, M. N. and Eteje, S. O. (2018). Computations of Geoid Undulation from Comparison of GNSS/Levelling with EGM 2008 for Geodetic Applications. International Journal of Scientific and Research Publications, Vol. 8, No. 10, pp 235-241. DOI: 10.29322/IJSRP.8.10.2018.p8230.

[20] Oluyori, P. D., Ono, M. N. and Eteje, S. O. (2019). Modelling of Orthometric heights from MultiNetworks of GNSS/Precise Levelling in FCT, Abuja. International Journal of Environment, Agriculture and Biotechnology (IJEAB), Vol. 4, No. 4, pp 1181-1194. DOI: 10.22161/ijeab.4443.

[21] Ono, M. N., Eteje, S. O. and Oduyebo, F. O. (2018). Comparative Analysis of DGPS and Total Station Accuracies for Static Deformation Monitoring of Engineering Structures. IOSR Journal of Environmental Science, Toxicology and Food Technology (IOSR-JESTFT), Vol. 12, No. 6, PP 1929. DOI: 10.9790/2402-1206011929.

[22] Sanlioglu, I., Maras, S. S. and Uysal, F. (2009). Determination of Orthometric Heights with RealTime Kinematic Surveying, Konya Sample, FIG Working Week, 2009.
[23] Shrivastava, P., Sahoo, L. and Stalin, M. (2015). Geoid Models for Indian Territory. IJSRSET, Vol. 1 No. 4, Pp 180-187.

[24] Sjöberg, L. E. (2000). On the Topographic Effects by the Stokes Helmert Method of Geoid and QuasiGeoid Determinations. Journal of Geodesy, Vol. 74 No. 2, Pp 255-268. DOI: 10.1007/s001900050284 in Kuczynska-Siehien, J., Lyszkowicz, A. and Birylo, M. (2016). Geoid Determination for the Area of Poland by the Least Squares Modification of Stokes' Formula. Acta Geodyn. Geomater, Vol. 13, No. 1, Pp 19-26.

[25] Ubajekwe, R. (2011). Geometric Geodesy; Unpublished Lecture Note of the Department of Surveying and Geoinformatics, Nnamdi Azikiwe University, Awka. 